\title{
Quantitative Screening of Secretory Protein Genes in Candidatus Liberibacter Asiaticus
}

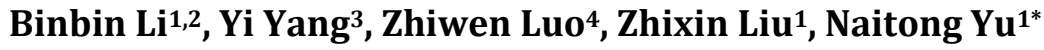 \\ ${ }^{1}$ Institute of Tropical Bioscience and Biotechnology, Chinese Academy of Tropical Agricultural Sciences, Haikou, China \\ ${ }^{2}$ Institute of Tropical Agriculture and Forestry, Hainan University, Haikou, China \\ ${ }^{3}$ Environment and Plant Protection Institute, Chinese Academy of Tropical Agricultural Sciences, Haikou, China \\ ${ }^{4}$ Tropical Fruit Trees Institute, Hainan Academy of Agricultural Sciences, Haikou, China \\ Email: *yunaitong@163.com
}

How to cite this paper: Li, B.B., Yang, Y., Luo, Z.W., Liu, Z.X. and Yu, N.T. (2018) Quantitative Screening of Secretory Protein Genes in Candidatus Liberibacter Asiaticus. American Journal of Plant Sciences, 9, 2408-2419.

https://doi.org/10.4236/ajps.2018.912174

Received: October 20, 2018

Accepted: November 16, 2018

Published: November 19, 2018

Copyright (๑) 2018 by authors and Scientific Research Publishing Inc. This work is licensed under the Creative Commons Attribution International License (CC BY 4.0).

http://creativecommons.org/licenses/by/4.0/ Open Access

\begin{abstract}
Huanglongbing (HLB) is the most destructive disease of citrus worldwide. The disease is caused by Candidatus Liberibacter spp., which is vectored by the psyllids Diaphorina citri Kuwayama and Trioza erytreae. Secretory proteins are important in bacterial pathogenesis and structure components. Some of them are expressed at a high level. To obtain the highly-expressed secretory protein genes (SPGs) for antiserum preparation, six candidate SPGs were chosen from Candidatus Liberibacter asiaticus by bioinformatic analysis and were further tested by qPCR and RT-qPCR methods, respectively. The result showed that two SPGs, 408 and pap (both are Flp pilus assembly protein genes), have relative high amounts of DNA and RNA transcripts of early HLB-infected green orange leaves. The 408 and pap genes were further constructed into the plant expression vector pCAMBIA1300 (GV1300: GFP) and expressed in tobacco leaf epidermal cells for subcellular localization analysis. The transient expression results indicated that the 408 protein is located in the nuclei and cytoplasm of tobacco leaf cells. However, the pap protein is located in the cytoplasm of tobacco leaf cells, which may help the pathogen invade into plant cells. This research is an important foundation for the preparation of the antiserum against Candidatus Liberibacter asiaticus and the early detection of HLB disease.
\end{abstract}

\section{Keywords}

Candidatus Liberibacter Asiaticus, Secretory Protein, DNA Amount, RNA Transcription, Subcellular Localization

\section{Introduction}

Citrus Huanglongbing (HLB), or greening disease, is a devastating disease that 
seriously threatens the development of the citrus industry globally [1] [2] [3]. Currently, the disease has been found in about 50 countries in the Asia, Africa, Oceania, South America, and North America regions. In China, 11 of the 19 major citrus-producing areas suffer from the HLB disease [1] [4] [5] [6]. Citrus Huanglongbing is caused by the pathogen of Candidatus Liberibacter asiaticus, africanus, and americanus, a gram-negative bacterium, which belongs to the genus Candidatus Liberibacter [7] [8]. There are no effective therapeutic agents or ideal resistant varieties for now. Integrated control management of HLB occurs mainly through controlling psyllids in field areas, removing HLB-infected trees, and planting healthy nursery trees. Of these three steps, the effective removal of infected trees depends on an accurate diagnosis of HLB at the early infection stage [8] [9] [10].

The content of Candidatus Liberibacter asiaticus is low from the infected trees and unevenly distributed in different parts of diseased plants [11] [12]. Therefore, establishment of an efficient and sensitive detection method for diagnosis of HLB at the early infection stage is a key factor for healthy development of the citrus industry. In recent years, with the fast development of the green orange industry in Hainan Province of China, the citrus Huanglongbing also spread rapidly [13]. At present, a rapid and large-scale field detection method for the pathogen mainly depends on protein technology, e.g., enzyme-linked immunosorbent assay (ELISA) [14] [15] [16]. However, a commercial large-scale detection method based on the protein level for HLB disease is yet to be developed.

There are six types of protein secretion system (types I-VI) in gram-negative bacteria [17] [18]. Each type of protein secretion system consists of a series of proteins with specific structures and functions. Through these protein secretion systems, gram-negative bacteria can release various toxic factors and effector factors to the extracellular environment or into the host cell to cause infection, which eventually leads to various diseases [18] [19]. Therefore, it is an ideal gene for the preparation of the antiserum against the Candidatus Liberibacter asiaticus because the content of secreted protein is at least thousands times higher than the number of its pathogen. Studies have shown that the pathogen of Candidatus Liberibacter asiaticus has an incomplete type III and type IV protein secretion systems but has a complete type I protein secretion system [20] [21].

In this study, six candidate secretory protein genes (SPGs) from Candidatus Liberibacter asiaticus were chosen by bioinformatics analysis and two SPGs of 408 and pap with relatively high DNA and RNA contents were identified by qPCR and RT-qPCR methods. Furthermore, the 408 protein was located in the nuclei and cytoplasm of tobacco cells, while the pap protein was localized in the cytoplasm of tobacco leaf cells by Agrobacterium-mediated transformation in tobacco leaf cells for transient expression. The study is an important foundation for the preparation of the antiserum against Candidatus Liberibacter asiaticus for the early detection and prevention of citrus HLB. 


\section{Materials and Methods}

\subsection{Materials}

In 2016, the QH sample was mixed from five early HLB-infected green orange leaves with asymptomatic in Qionghai County, Hainan Province, and the QZ sample was mixed from another five early HLB-infected green orange leaves with asymptomatic in Qiongzhong County, Hainan Province. Both pathogens of $\mathrm{QH}$ and QZ were identical with the Candidatus Liberibacter asiaticus psy62 isolate (GenBank accession number: CP001677.5) [22]. Wild-type Nicotiana benthamiana ( $N$. benthamiana) (Ferox genus) was kept in the Laboratory of Molecular Virology, Institute of Tropical Bioscience and Biotechnology (ITBB), Chinese Academy of Tropical Agricultural Sciences (CATAS). The GV1300 plasmid (pCAMBIA1300: GFP) was provided by Professor Ming Peng of ITBB, CATAS.

\subsection{Primers Design, DNA, and cDNA Preparation}

In order to identify one or two high-expression SPGs, six SPGs were chosen from the different protein secretory systems according to the complete genome sequence of Candidatus Liberibacter asiaticus [22] (Table 1). Based on the nucleotide sequences of these SPGs, 6 primer-pairs of the 408, 24A, fATP, pap, msp, and 377 genes were designed for qPCR or RT-qPCR using the online website (https://www.idtdna.com/Scitools/Applications/RealTimePCR/) (Table 2). $18 S$ rRNA of citrus was used as an internal reference gene [23] (Table 2). All primers were synthesized by the Beijing Genomics Institute (BGI).

Total DNA extraction of the QH and QZ samples was performed according to the manufacturer's instructions with a Plant Genomic DNA Kit (TIANGEN BIOTECH, Beijing, China) and total RNA extraction was performed according to the Trizol Universal Regent (TIANGEN BIOTECH, Beijing, China). First-strand cDNA was synthesized from $2.0 \mu \mathrm{L}$ of total RNA using $0.5 \mu \mathrm{L}$ of random hexamer primer $(10 \mu \mathrm{M})$ and the Fast Quant RT Kit (with gDNase) (TIANGEN BIOTECH, Beijing, China).

\subsection{Screening of Candidate SPGs and Establishment of Real-Time Quantitative PCR (qPCR)}

In order to measure the efficiency and correlation coefficients of six SPG primer pairs in qPCR, the initial amplified DNA template was further diluted to $1: 10^{-1}$, $1: 10^{-2}, 1: 10^{-3}, 1: 10^{-4}$, and $1: 10^{-5}$ by $\mathrm{ddH}_{2} \mathrm{O}$, and these samples were used to establish the standard curves by each pair primer in the Stratagene Mx3005 machine. The results showed that six $\mathrm{qPCR}$ reactions by the specific primer pairs amplified SPGs highly efficiently (efficiencies of $86.8 \%$ to $92.2 \%$ ) with correlation coefficients between 0.981 and 0.999 .

In order to measure the relative DNA amounts and their RNA expression levels of six SPGs, qPCR and RT-qPCR analyses were performed on an Agilent Stratagen Mx3005P instrument using the Hieff ${ }^{\mathrm{TM}}$ qPCR SYBR Green Master Mix with Low Rox Plus (Yeasan, Shanghai, China) according to the instructions, and 
Table 1. Characteristic summary of six candidate secretory protein genes from Candidatus liberibacter asiaticus.

\begin{tabular}{ccccc}
\hline Protein & Region name & Protein ID & Protein function & Type of protein \\
\hline 408 & T2SS-T3SS pilN & ACT57211.2 & Flp pilus assembly protein, secretin CpaC & Secreted protein \\
24A & Peptidase A24 & ACT57202.1 & Type II secretory pathway, prepilin signal peptidase PulO and & Type II secretory pathway \\
pap & CpaC & ACT57200.1 & Flp pilus assembly protein, secretin CpaC & Secreted protein \\
msp & FliN & ACT57161.1 & Flagellar motor switch/Predicted secreted (periplasmic) protein & Secreted protein \\
fATP & fliI & ACT57157.1 & Flagellar biosynthesis/type III secretory pathway ATPase & Type III secretory pathway \\
377 & COG5462 & ACT57577.1 & Predicted secreted (periplasmic) protein & Secreted protein \\
\hline
\end{tabular}

The database sources: NCBI Reference Sequence database (http://www.ncbi.nlm.nih.gov).

Table 2. Primers used in this study.

\begin{tabular}{|c|c|c|c|c|}
\hline Gene & Primer name & Primer sequences ( $\left.5^{\prime}-3^{\prime}\right)$ & Length (bp) & \\
\hline \multirow[b]{2}{*}{408} & $408-\mathrm{F}$ & CTGTACTCCAAGATGCCTACC & \multirow[b]{2}{*}{131} & \\
\hline & $408-\mathrm{R}$ & CGTGCCTATCATGCTTGTTTC & & \\
\hline \multirow{2}{*}{ PAP } & PAP-F & AGCCAGTAATCGGAGTCAATG & \multirow{2}{*}{119} & \\
\hline & PAP-R & TCATCTTTCAATAACCCCGCC & & \\
\hline \multirow{2}{*}{ MSP } & MSP-F & AGACATGTGCCATTTTAAGTGC & \multirow{2}{*}{96} & \\
\hline & MSP-R & TCTATCTGTTATGCGAATCGTGT & & \\
\hline \multirow{2}{*}{377} & $377-\mathrm{F}$ & CCAAGAGAACTGTAGAAAGGCG & \multirow{2}{*}{147} & Real-time PCR \\
\hline & $377-\mathrm{R}$ & AGAAGTATAACCTCCСCACTCG & & assay \\
\hline \multirow{2}{*}{$24 \mathrm{~A}$} & $24 \mathrm{~A}-\mathrm{F}$ & GGGTGGAGGGGATGTAAAATT & \multirow{2}{*}{113} & \\
\hline & $24 \mathrm{~A}-\mathrm{R}$ & GACAGATAATATTCCGCCTAAAATAGC & & \\
\hline \multirow{2}{*}{ fATP } & fATP-F & ATAGCGGATTCTGTTCGTAGC & \multirow{2}{*}{136} & \\
\hline & fATP-R & ATCAGCACTCCAAGCCTTATC & & \\
\hline \multirow{2}{*}{ 18S rRNA } & $18 \mathrm{~S}$ rRNA-F & TCGGGTGTTTTCACGTCTCA & \multirow{2}{*}{120} & \\
\hline & 18S rRNA-R & TGGATGCCGCTGGGAAGC & & \\
\hline \multirow{2}{*}{408} & 408-gF & CGCGTCGACTTGCATCGTAAGCGCC (Sal I) & \multirow{2}{*}{423} & \\
\hline & 408-gR & CGCACTAGTCCTGACGGGAGGAGAGGAG (Spe I) & & $\begin{array}{l}\text { Recombinant } \\
\text { plasmids }\end{array}$ \\
\hline \multirow{2}{*}{ pap } & pap-gF & CGCGTCGACATGAGGTATTTGCAACGCAC (Sal I) & \multirow{2}{*}{1440} & construction \\
\hline & pap-gR & CGCGGATCCTTTATAAATAAAACCAATTGCACC (BamH I) & & \\
\hline \multirow{2}{*}{ GV1300 } & $1300-\mathrm{F}$ & AACTTGTGGCCGTTTACGTCG & \multirow{2}{*}{207} & Primers for \\
\hline & $1300-\mathrm{R}$ & TTTGGAGAGAACACGGGGGAC & & GV1300 \\
\hline
\end{tabular}

Note: The bold sequences represent the restriction enzymes.

each gene was measured three times independently. The total DNA from healthy green orange leaves was used as a negative control. The qPCR or RT-qPCR mixture was $10 \mu \mathrm{L}$ of Hieff ${ }^{\mathrm{TM}} \mathrm{qPCR}$ SYBR Green Master Mix, $0.4 \mu \mathrm{L}$ of forward primer $(10 \mu \mathrm{M}), 0.4 \mu \mathrm{L}$ of reverse primer $(10 \mu \mathrm{M}), 1 \mu \mathrm{L}$ of template DNA or cDNA, and $8.2 \mu \mathrm{L}$ of $\mathrm{ddH}_{2} \mathrm{O}$. The $\mathrm{qPCR}$ and RT-qPCR programs involved pre-denaturing at $95^{\circ} \mathrm{C}$ for $5 \mathrm{~min}$, followed by 40 cycles of denaturing at $95^{\circ} \mathrm{C}$ for $10 \mathrm{~s}$, annealing at $55^{\circ} \mathrm{C}$ for $30 \mathrm{~s}$, extending at $72^{\circ} \mathrm{C}$ for $20 \mathrm{~s}$, and a dissolution curves program 
using the Agilent Strata Mx3005P instrument.

\subsection{Plasmid Construction and Subcellular Localization of 408 and Pap Proteins}

The 408 gene was amplified with the $408-\mathrm{gF} / 408-\mathrm{gR}$ primers, while the pap gene was amplified by using the pap-gF/pap-gR primers (Table 2). The PCR reaction was conducted using PrimeSTAR HS DNA Polymerase kit (Takara, Dalian, China): $0.5 \mu \mathrm{L}$ of PrimeSTAR HS DNA Polymerase $(2.5 \mathrm{U} / \mu \mathrm{L}), 10 \mu \mathrm{L}$ of $5 \times$ PrimeSTAR Buffer ( $\mathrm{Mg}^{2+}$ plus), $4 \mu \mathrm{L}$ of dNTP Mixture (2.5 mM each), $2 \mu \mathrm{L}$ of $\mathrm{F} / \mathrm{R}(5 \mu \mathrm{M})$ primer, and $2 \mu \mathrm{L}$ of total DNA, and $\mathrm{ddH}_{2} \mathrm{O}$ was added up to $50 \mu \mathrm{L}$. The PCR program involved pre-denaturing at $98^{\circ} \mathrm{C}$ for $3 \mathrm{~min}$, followed by 35 cycles of denaturing at $98^{\circ} \mathrm{C}$ for $30 \mathrm{~s}$, annealing at $55^{\circ} \mathrm{C}$ for $30 \mathrm{~s}$, extending at $72^{\circ} \mathrm{C}$ for $50 \mathrm{~s}$; and finally, the reaction was terminated by post-extending at $72^{\circ} \mathrm{C}$ for $10 \mathrm{~min}$. The amplified target fragments of 408 and pap were gel-extracted by using the DNA Gel Extraction Kit (Omega Bio-Tek, Doraville, GA, USA) and subsequently, cloned into the plant expression vector GV1300 using T4 DNA ligase (Takara, Dalian, China). The recombinant plasmid was further transformed into Escherichia coli (E. coli) Trans 5a competent cells (TransGen, Beijing, China), and three positive clones were selected for bidirectional sequencing by 1300-F and 1300-R primers at Thermo Fisher (Guangzhou, China).

The recombinant plasmids of GV1300, GV1300-408, and GV1300-pap were transformed into Agrobacterium tumefaciens GV3101 competent cells by the freeze-thaw method, as described in Sparkes and Al [24]. The transfected tobacco leaves were cut into pieces of $1 \mathrm{~cm} \times 1 \mathrm{~cm}$, and fluorescence images were visualized on a microscope (FluoView FV1000D IX81; Olympus, Tokyo, Japan) to observe the subcellular localization of the fusion protein under wavelengths of $488 \mathrm{~nm}$ and $546 \mathrm{~nm}$.

\section{Results}

\subsection{Preparation of Total DNA and cDNA from Diseased Green Orange Leaves}

Total DNA extracted from two mixed samples were visualized on a $1 \%$ agarose gel, and the specific DNA bands of more than $10 \mathrm{kbp}$ in lengths were consistent with the predicted sizes (data not shown). Total RNA samples were also extracted from these two samples and were visualized on a 1\% agarose gel (data not shown). The results indicated that the RNA bands of $28 \mathrm{~S}, 18 \mathrm{~S}$, and $5 \mathrm{~S}$ were abundant which suggests that a high quality of total RNA was obtained. The total RNA was further used to synthesize the first strand cDNA $\left(1^{\text {st }} \mathrm{cDNA}\right)$ which subsequently could be used for RT-qPCR.

\subsection{Screening of Candidate SPGs from HLB-Infected Green Orange Leaves}

Analysis of the real-time qPCR showed that the amplification plot of six SPGs 
and the internal reference gene shown in the dissociation curve of QH sample (Figure 1(a)), similar result was observed in QZ sample. Further analysis indicated that the DNA contents of the 408 and pap genes were 26.48 and 9.36 times that of the 377 gene, while the other genes were $2.17-4.11$ times that of the

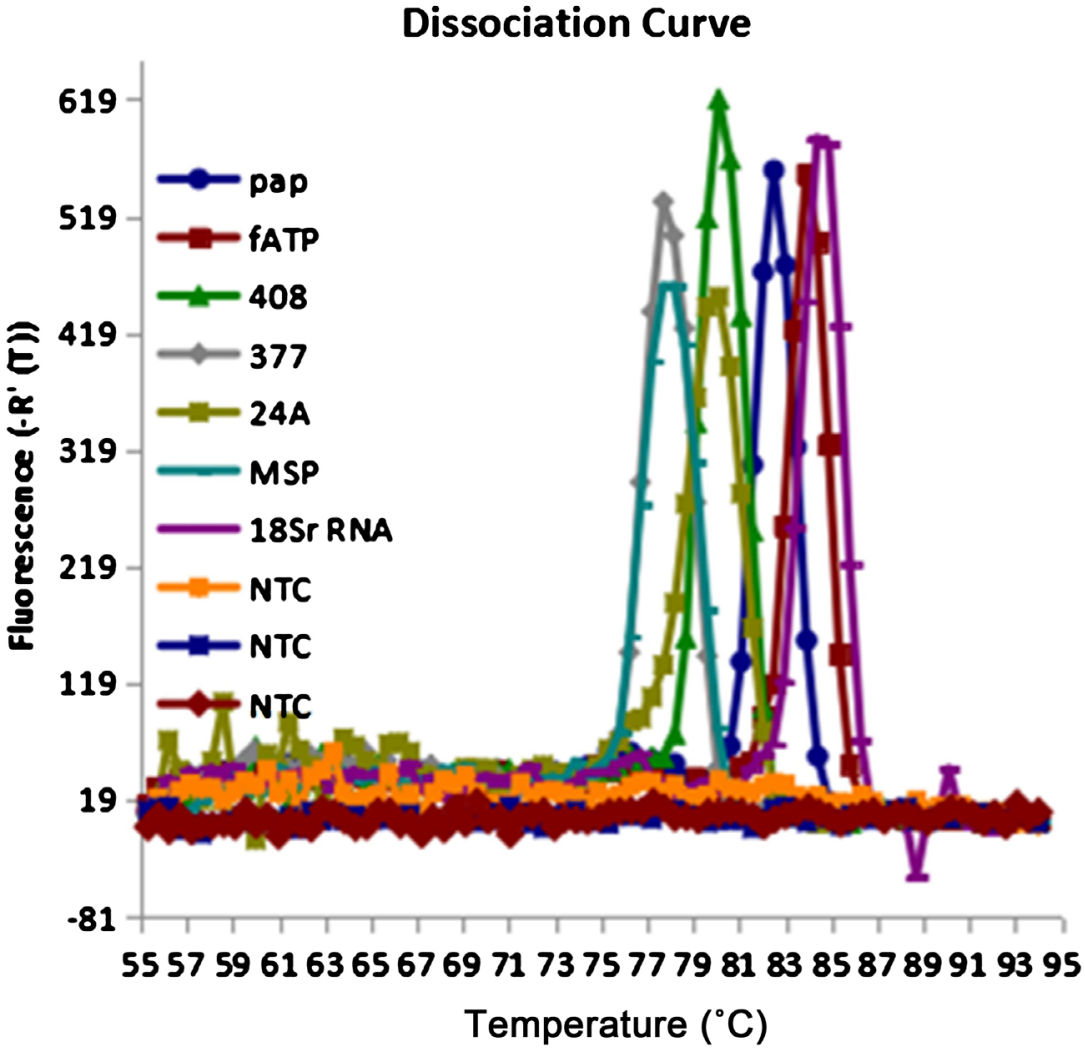

(a)

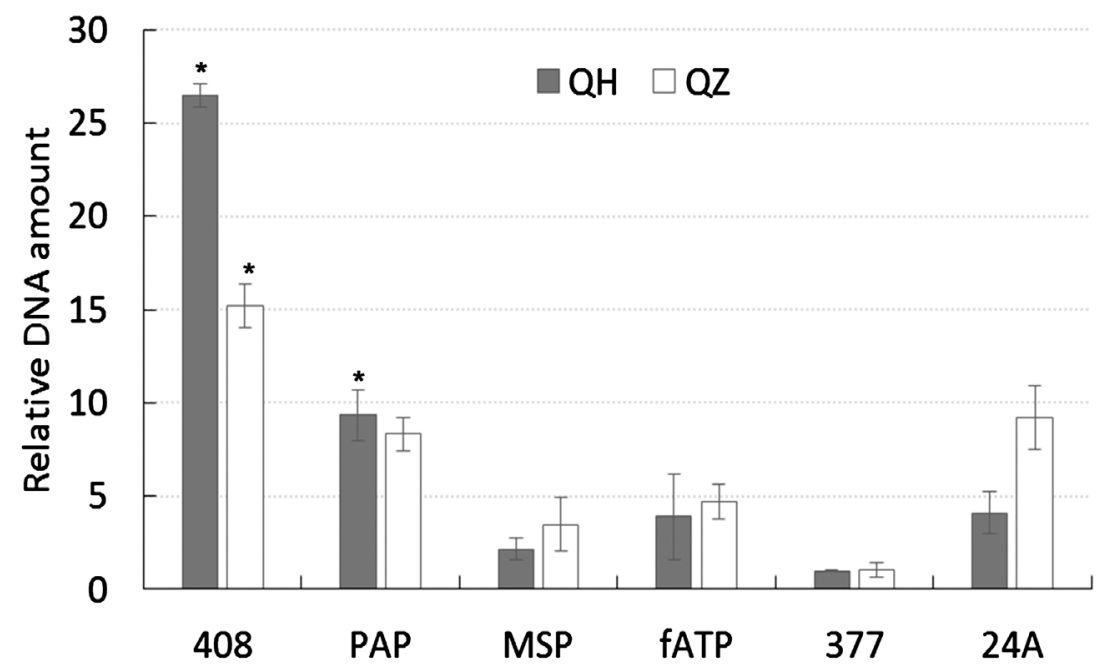

(b)

Figure 1. (a) The melt curves of six selected candidated secretory protein genes and $18 \mathrm{~S}$ rRNA by real-time quantitative PCR; (b) Relative DNA amount of six selected candidate secretory protein genes in $\mathrm{QH}$ and $\mathrm{QZ}$ samples. Statistical analysis was performed using student's t-test. “`” represents $\mathrm{P}<0.05$. 
377 gene in the QH sample (Figure 1(b)). In the QZ sample, the DNA contents of the 408 and pap genes were 15.20 and 8.35 times that of the 377 gene, while the DNA content of the $24 A$ gene was also relatively high, about 9.22 times that of the 377 gene (Figure 1(b)). In summary, the relative DNA contents of the 408, pap, and $24 A$ genes were relatively high in $\mathrm{QH}$ and $\mathrm{QZ}$ samples.

The results from the RT-qPCR quantification did not match the DNA amount shown in the qPCR reactions. Of these six SPGs, only the 408 and pap genes had amplification curves, and the Ct value was between 15 and 35. Other genes did not have an obvious amplification curve, or their $\mathrm{Ct}$ value was more than 35 which should be insignificant (Very low amount or unspecific amplification). Further analysis revealed that the relative transcription level of the 408 gene was 2.43 higher than the transcription level of the pap gene in $\mathrm{QH}$ sample. In the QZ sample, the relative transcription level of the 408 gene was 9.45 higher than the transcription level of pap gene, and the relative transcript RNA level was much higher than that of the 408 gene in the QH sample (Figure 2). In this study, two relatively high transcription levels of SPGs were screened from the ten candidate SPGs.

\subsection{Subcellular Localization of 408 and Pap Proteins}

In order to further clarify the distribution of the 408 and pap proteins in the host cells, the recombinant plasmids of GV1300-408 and GV1300-pap were transformed into Agrobacterium tumefaciens GV1301 competent cells. Then, the positive clones were identified by colony PCR (Single colony was used as template), as described above. After injection of GV1300-408/GV1301 and GV1300-pap/GV1301 into the tobacco leaves, fluorescence images were visualized

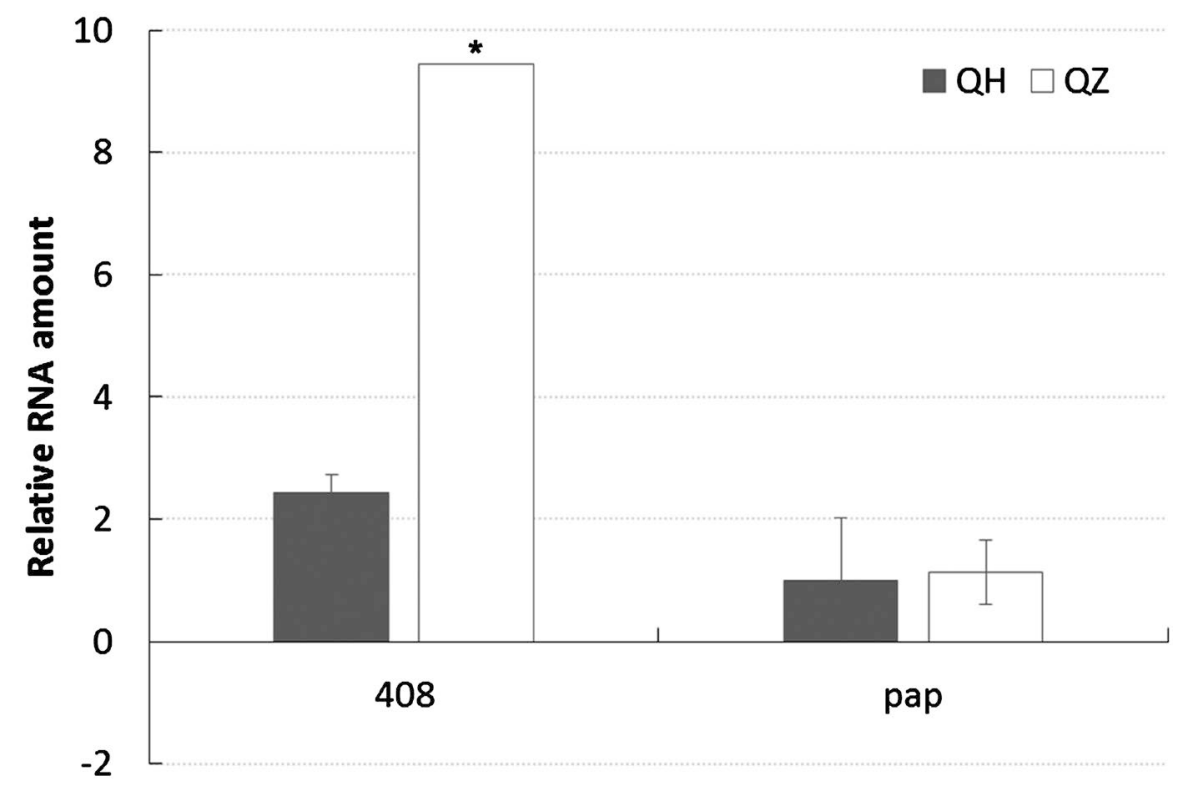

Figure 2. Relative RNA amount of 408 and pap candidate secretory protein genes in QH and QZ samples. Statistical analysis was performed using student's t-test. “»” represents $\mathrm{P}$ $<0.05$. 
by microscopy at 72 hours post inoculation (h.p.i.). The green fluorescence signal from the 408-GFP fusion protein was observed in the nuclei and cytoplasm of tobacco leaf cells, while the green fluorescence signal of the pap-GFP fusion protein was observed in the cytoplasm of tobacco leaf cells. These results indicate that the 408 protein localizes in the nucleus and cytoplasm tobacco mesophyll cells, but the pap protein localizes in the cytoplasm of tobacco leaf cells. In addition, the GFP protein is localized in the cytoplasm and the nuclei of tobacco mesophyll cells (Figure 3).

\section{Discussion}

Bacteria-secreted proteins play important roles in pathogenicity and infection in host cells [25] [26]. Briefly, pathogenic bacteria have a number of different protein secretion systems and secrete virulence factors extracellularly or directly to the host via these secretion systems. Currently, it is known that there are at least
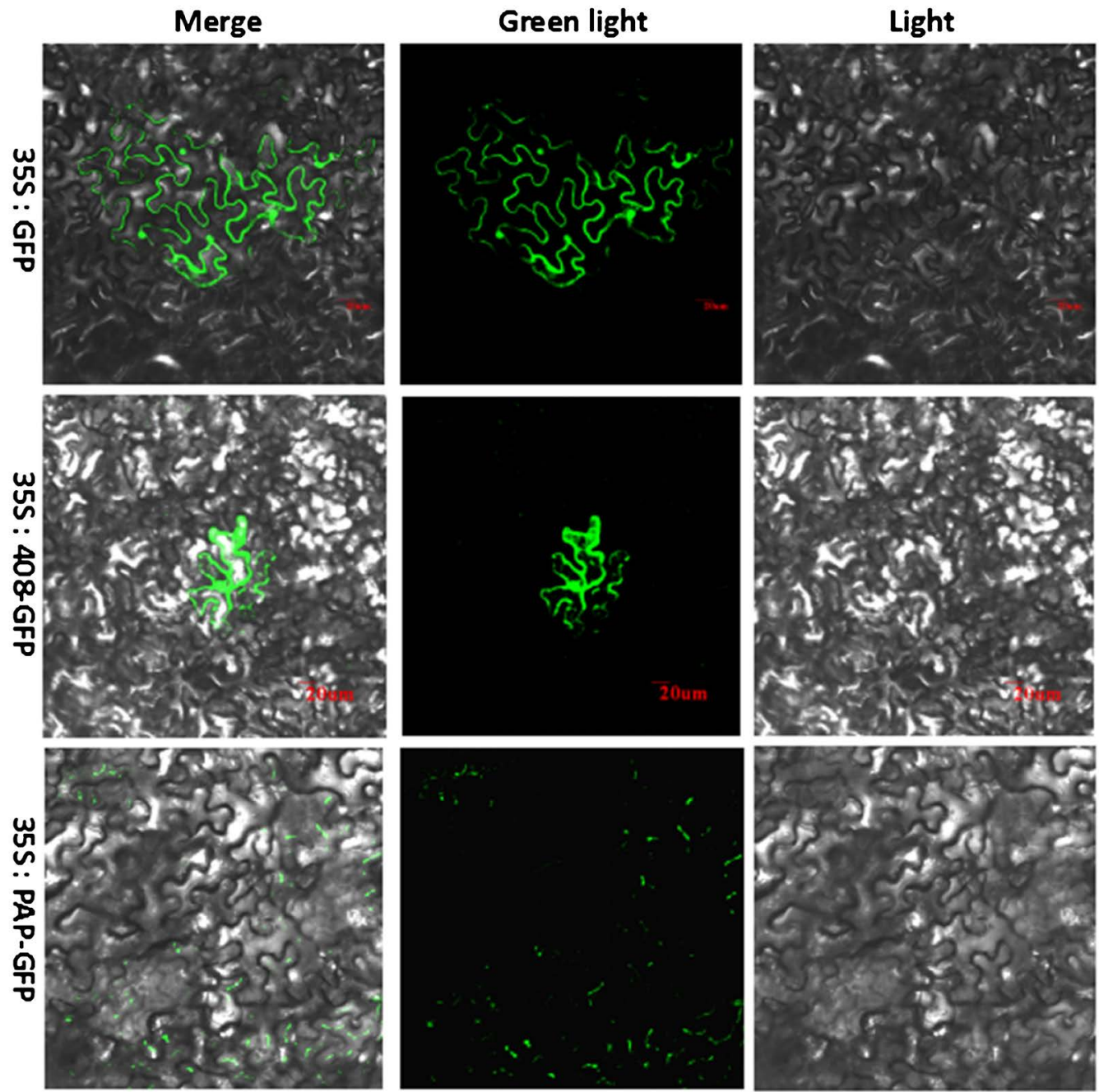

Figure 3. Subcellular localization of GFP, 408-GFP and PAP-GFP in tobacco leaf cells under the light of $488 \mathrm{~nm}$ and $546 \mathrm{~nm} .35 \mathrm{~S}$, a constitutive promoter from the cauliflower mosaic virus; GFP, green fluorescent protein; Bar represents $20 \mu \mathrm{m}$. 
six protein secretion systems in Gram-negative bacteria [17] [18]. Candidatus Liberibacter asiaticus has incomplete type III and type IV protein secretion systems and a complete type I protein secretion system. In this study, the obtained 408 gene was secreted by the type III secretion system, while the pap gene was secreted by the type IV secretion system [22]. The Flp pilus, which is assembled by the proteins encoded by the $f l p$ (fimbrial low-molecular-weight protein), may play an important role in bacterial adherence. Here, both of 408 and pap proteins are flp pilus assembly proteins. Pili, flagella, and other adhesive structures usually assemble at the cell surface of gram-negative bacteria. The ability of diverse bacteria to adhere to host cell surfaces is an important property and a critical step in colonization [27]. Therefore, 408 and pap may be involved in these adhesive organelle assemblies via the extracellular nucleation-precipitation pathway [28]. Furthermore, subcellular localization analyses indicated that the 408 protein is located in the nuclei and cytoplasm of tobacco leaf cells. This suggests that the 408 gene may have other functions besides the formation of flagella on the bacterial surface. However, the pap protein was shown to be located in the cytoplasm of tobacco leaf cells and may interact with host cells to help pathogens invade into plant cells.

At present, the effective detection methods of pathogen microscopy, loop-mediated isothermal amplification (LAMP), PCR and real-time quantitative PCR were available for HLB diagnosis [3] [29] [30] [31] [32] [33]. However, a protein detection technology for citrus Huanglongbing with convenience and high sensitivity at a large-scale needs to be developed. Although Yuan et al. and Liu et al. reported monoclonal antibodies against Candidatus Liberibacter asiaticus [34] [35] [36], there are no commercial products available yet. In order to prepare an antiserum against the Candidatus Liberibacter asiaticus for the early detection and prevention of citrus HLB, six SPGs were selected from different protein secretion systems of Candidatus Liberibacter asiaticus and tested by qPCR and RT-qPCR, and two SPGs of 408 and pap with relatively high DNA contents and their transcription level were identified. This provides an important scientific basis for the preparation of an antiserum against Candidatus Liberibacter asiaticus and the early detection and prevention of citrus HLB.

\section{Acknowledgements}

This work was supported by the Major Science and Technology Program of Hainan Province (grant number ZDKJ2017003), the Young Elite Scientists Sponsorship Program by CSTC (project no. CSTC-QN201704), and the Key Laboratory of Tropical Fruit Tree Biology of Hainan Province (grant number KFZX2017002).

\section{Conflicts of Interest}

The authors declare no conflicts of interest regarding the publication of this paper. 


\section{References}

[1] Bové, J.M. (2006) Huanglongbing: A Destructive, Newly-Emerging, Century-Old Disease of Citrus. Journal of Plant Pathology, 88, 7-37.

[2] Gottwald, T.R. (2010) Current Epidemiological Understanding of Citrus Huanglongbing. Annual Review of Phytopathology, 48, 119-139.

https://doi.org/10.1146/annurev-phyto-073009-114418

[3] Arratia-Castro, A.A., Santos-Cervantes, M.E., Arce-Leal, Á.P., Espinoza-Mancillas, M.G., Rodríguez Negrete, E.A., Méndez-Lozano, J., Arocha-Rosete, Y. and Leyva-López, N.E. (2016) Detection and Quantification of 'Candidatus Phytoplasma asteris' and 'Candidatus Liberibacter Asiaticus' at Early and Late Stages of Huanglongbing Disease Development. Canadian Journal of Plant Pathology, 38, 411-421. https://doi.org/10.1080/07060661.2016.1243586

[4] Fan, G.C., Bo, L., Ru-Jian, W.U., Tao, L.I., Cai, Z.J. and Chong, K.E. (2009) Thirty Years of Research on Citrus Huanglongbing in China. Fujian Journal of Agricultural Sciences, 24,183-190.

[5] Bai, Z.Q. (2012) Occurrence Dynamics of Citrus Huanglongbing in P.R. China and Population Differentitation of 'Candidatus Liberibacter Asiaticus'. Master Dissertation, Southwest University, Chongqing.

[6] Da, G.J., Douhan, G.W., Halbert, S.E., Keremane, M.L., Lee, R.F., Vidalakis, G. and Zhao, H. (2016) Huanglongbing: An Overview of a Complex Pathosystem Ravaging the World's Citrus. Journal of Integrative Plant Biology, 58, 373-387.

https://doi.org/10.1111/jipb.12437

[7] Villechanoux, S., Garnier, M., Renaudin, J. and Bové, M. (1992) Detection of Several Strains of the Bacterium-Like Organism of Citrus Greening Disease by DNA Probes. Current Microbiology, 24, 89-95. https://doi.org/10.1007/BF01570903

[8] Gottwald, T.R., Graça, J.V.D. and Bassanezi, R.B. (2007) Citrus Huanglongbing: The Pathogen and Its Impact. Plant Health Progress, 1, 0906-0901.

https://doi.org/10.1094/PHP-2007-0906-01-RV

[9] Iftikhar, Y., Rauf, S., Shahzad, U. and Zahid, M.A. (2016) Huanglongbing: Pathogen Detection System for Integrated Disease Management-A Review. Journal of the Saudi Society of Agricultural Sciences, 15, 1-11. https://doi.org/10.1016/j.jssas.2014.04.006

[10] Munir, S., He, P., Wu, Y., He, P., Khan, S., Huang, M., Cui, W., He, P. and He, Y. (2018) Huanglongbing Control: Perhaps the End of the Beginning. Microbial Ecology, 76, 192-204. https://doi.org/10.1007/s00248-017-1123-7

[11] Li, W., Laurene, L. and Johns, H. (2009) Quantitative Distribution of 'Candidatus Liberibacter Asiaticus' in Citrus Plants with Citrus Huanglongbin. Phytopathology, 99, 139-144. https://doi.org/10.1094/PHYTO-99-2-0139

[12] Lu, L., Fan, G., Hu, X., Zhang, L., Huang, Z. and Chen, G. (2011) PCR Detection of Huanglongbing Pathogen in Different Parts of Citrus Plants in the Field and Analysis of the Cause of the Disease. Plant Protection, 23, 271-312.

[13] Wu, X., Meng, C., Wang, G., Liu, Y., Zhang, X., Yi, K. and Peng, J. (2016) Rapid and Quantitative Detection of Citrus Huanglongbing Bacterium 'Candidatus Liberibacter Asiaticus' by Real-Time Fluorescent Loop-Mediated Isothermal Amplification Assay in China. Physiological \& Molecular Plant Pathology, 94, 1-7. https://doi.org/10.1016/j.pmpp.2016.03.001

[14] Vetten, H.J., Ehlers, U. and Paul, H.L. (2010) Detection of Potato Viruses Y and A in Tubers by Enzyme-Linked Immunosorbent Assay after Natural and Artificial 
Break of Dormancy. Journal of Phytopathology, 108, 41-53. https://doi.org/10.1111/j.1439-0434.1983.tb00562.x

[15] Selvarajan, R., Balasubramanian, V. and Gayathrie, T. (2016) Highly Efficient Immunodiagnosis of Episomal Banana Streak MY Virus Using Polyclonal Antibodies Raised against Recombinant Viral-Associated Protein. Journal of Phytopathology, 164, 497-508. https://doi.org/10.1111/jph.12475

[16] Webster, C.G., Turechek, W.W., Li, W., Kousik, C.S. and Adkins, S. (2016) Development and Evaluation of ELISA and qRT-PCR for Identification of Squash Vein Yellowing Virus in Cucurbits. Plant Disease, 101, 178-185. https://doi.org/10.1094/PDIS-06-16-0872-RE

[17] Costa, T.R., Felisberto-Rodrigues, C., Meir, A., Prevost, M.S., Redzej, A., Trokter, M. and Waksman, G. (2015) Secretion Systems in Gram-Negative Bacteria: Structural and Mechanistic Insights. Nature Reviews Microbiology, 13, 343-359. https://doi.org/10.1038/nrmicro3456

[18] Yu, L.Z., Liu, F.J., Yan, N.N., Cheng, X., Li, Y.Z. and Guo, Y.Z. (2017) Progress on Secretion Systems and Secretory Products of Gram-Negative Bacteria. Progress in Veterinary Medicine, 38, 80-84.

[19] Clark, K., Franco, J.Y., Schwizer, S., Pang, Z., Hawara, E., Liebrand, T.W.H., Pagliaccia, D., Zeng, L., Gurung, F.B., Wang, P., Shi, J., Wang, Y., Ancona, V., van der Hoorn, R.A.L., Wang, N., Coaker, G. and Ma, W. (2018) An Effector from the Huanglongbing-Associated Pathogen Targets Citrus Proteases. Nature Communications, 9, 1718. https://doi.org/10.1038/s41467-018-04140-9

[20] Hao, J. (2011) Construction Expression and Purification Research of Citrus Huanglongbing Serralysin Protein. Master Dissertation, Huazhong Agricultural University, Wuhan.

[21] Hou, W.Z. (2014) Expression and Purification of Citrus Huanglongbing Serralysin and Molecular Detection of Two Important Pathogens. Master Dissertation, Huazhong Agricultural University, Wuhan.

[22] Duan, Y.P., Zhou, L.J., Hall, D.G., Li, W.B., Doddapaneni, H., Lin, H., Liu, L., Vahling, C.M., Gabriel, D.W. and Williams, K.P. (2009) Complete Genome Sequence of Citrus Huanglongbing Bacterium, "Candidatus Liberibacter Asiaticus" Obtained through Metagenomics. Molecular Plant-Microbe Interactions, 22, 1011-1020. https://doi.org/10.1094/MPMI-22-8-1011

[23] Yan, J., Yuan, F., Long, G., Qin, L. and Deng, Z. (2012) Selection of Reference Genes for Quantitative Real-Time RT-PCR Analysis in Citrus. Molecular Biology Reports, 39, 1831-1838. https://doi.org/10.1007/s11033-011-0925-9

[24] Sparkes, I.A. and Al, E. (2006) Rapid, Transient Expression of Fluorescent Fusion Proteins in Tobacco Plants and Generation of Stably Transformed Plants. Nature Protocols, 1, 2019-2025. https://doi.org/10.1038/nprot.2006.286

[25] Barny, M.A., Gaudriault, S., Brisset, M.N. and Paulin, J.P. (1999) HRP Secreted Proteins: Their Role in Pathogenicity and HR Elicitation. Acta Horticulturae, 489, 353-358. https://doi.org/10.17660/ActaHortic.1999.489.62

[26] Abby, S.S. and Rocha, E.P.C. (2016) Identification of Protein Secretion Systems in Bacterial Genomes Using MacSyFinder. Methods in Molecular Biology, 1615, 1-21.

[27] Li, T., Xu, Z., Zhang, T., Li, L., Chen, H. and Zhou, R. (2012) The Genetic Analysis of the Flp Locus of Actinobacillus pleuropneumoniae. Archives of Microbiology, 194, 167-176. https://doi.org/10.1007/s00203-011-0741-6

[28] Zav'Yalov, V., Zavialov, A., Zav'Yalova, G. and Korpela, T. (2010) Adhesive Organelles of Gram-Negative Pathogens Assembled with the Classical Chaperone/Usher 
Machinery: Structure and Function from a Clinical Standpoint. FEMS Microbiology Reviews, 34, 317-378. https://doi.org/10.1111/j.1574-6976.2009.00201.x

[29] Okuda, M., Matsumoto, M., Tanaka, Y., Subandiyah, S. and Iwanami, T. (2005) Characterization of the tufB-secE-nusG-rplKAJL-rpoB Gene Cluster of the Citrus Greening Organism and Detection by Loop-Mediated Isothermal Amplification. Plant Disease, 89, 705-711. https://doi.org/10.1094/PD-89-0705

[30] Li, W., Hartung, J.S. and Levy, L. (2006) Quantitative Real-Time PCR for Detection and Identification of Candidatus Liberibacter Species Associated with Citrus Huanglongbing. Journal of Microbiological Methods, 66, 104-115. https://doi.org/10.1016/j.mimet.2005.10.018

[31] Tanaka, F.A.O., Coletta-Filho, H.D., Alves, K.C.S., Spinelli, M.O., Machado, M.A. and Kitajima, E.W. (2007) Detection of the "Candidatus Liberibacter Americanus" in Phloem Vessels of Experimentally Infected Cataranthus Roseus by Scanning Electron Microscopy Detecção de Candidatus Liberibacter americanus em vasos de floema de Catharantus roseus infectados exper. Tropical Plant Pathology, 32, 519-519.

[32] Fujikawa, T., Miyata, S. and Iwanami, T. (2013) Convenient Detection of the Citrus Greening (Huanglongbing) Bacterium "Candidatus Liberibacter Asiaticus” by Direct PCR from the Midrib Extract. PLoS ONE, 8, e57011.

https://doi.org/10.1371/journal.pone.0057011

[33] Fang, D., Paul, C., Brlansky, R. and Hartung, J.S. (2017) Immune Tissue Print and Immune Capture-PCR for Diagnosis and Detection of Candidatus Liberibacter Asiaticus. Scientific Reports, 7, Article No. 46467. https://doi.org/10.1038/srep46467

[34] Yuan, Q., Jordan, R., Brlansky, R.H., Minenkova, O. and Hartung, J. (2016) Development of Single Chain Variable Fragment (scFv) Antibodies against Surface Proteins of "Ca. Liberibacter Asiaticus". Journal of Microbiological Methods, 122, 1-7. https://doi.org/10.1016/j.mimet.2015.12.015

[35] Liu, H., Atta, S. and Hartung, J.S. (2017) Characterization and Purification of Proteins Suitable for the Production of Antibodies against "Ca. Liberibacter Asiaticus". Protein Expression and Purification, 139, 36-42. https://doi.org/10.1016/j.pep.2017.07.010

[36] Pagliaccia, D., Shi, J., Pang, Z., Hawara, E., Clark, K., Thapa, S.P., De Francesco, A.D., Liu, J., Tran, T.T., Bodaghi, S., Folimonova, S.Y., Ancona, V., Mulchandani, A., Coaker, G., Wang, N., Vidalakis, G. and Ma, W. (2017) A Pathogen Secreted Protein as a Detection Marker for Citrus Huanglongbing. Frontiers in Microbiology, 8, 2041. https://doi.org/10.3389/fmicb.2017.02041 